\title{
Liquid Planning: Toward Sustainability Through the Lens of Water
}

MARÍA ARQUERO DE ALARCÓN, JENNIFER MAIGRET

Volume 1, Fall 2013

DOI: http://dx.doi.org/10.3998/mjs.12333712.0001.010

\section{ABSTRACT}

The development of collaborative, cross-disciplinary, pedagogical frameworks is an institutional priority at the University of Michigan that promises innovative advances in research at the intersection of ecological and urban dynamics. The Taubman College of Architecture and Urban Planning is well poised to foster models of scholarship and teaching, particularly those that can contribute to a better understanding of the relationships between environmental processes and the design of our built environment. Initiated in Fall 2011, Liquid Planning, a three-credit advanced graduate seminar course, enrolls students from architecture, environmental planning and policy, landscape architecture, sustainable systems, urban design, and urban planning to bring a wide range of expertise to the classroom around a shared urban challenge involving urban stormwater management.

Liquid Planning is a collaborative teaching initiative that develops methods of transdisciplinary practice. In particular, the course explores approaches to sustainable design and revitalization through an investigation into the common mis-registration between urban infrastructure and natural water systems. Because water is a critical component in an understanding of past and present conditions and future paradigms for metropolitan regions, Liquid Planning utilizes watershed thinking to foster approaches that bridge scales, work within temporally dynamic systems, and establish processes that transcend established administrative boundaries. In these ways, Liquid Planning recognizes the importance of design disciplines in the innovation of more sustainable construction practices.

Keywords: trans-disciplinary, design, urban dynamics, stormwater infrastructure, visualization. 
Research Support: The initial development of the course was supported by the Center for Research on Learning and Teaching at the University of Michigan, through the Teaching with Technology and Faculty Development Fund Grants. The work developed in the Hope Village Initiative was funded by the Graham Institute for Environmental Sustainability through its partnership with Focus Hope. More information about the Hope Village Initiative can be found here: http://www. graham.umich.edu/news/u-m-funds-sustainability-projects-detroits-focus-hope.

About the authors: María Arquero de Alarcón (marquero@umich.edu) and Jennifer Maigret (maigretj@umich.edu) are partners at MAde-studio and assistant professors at Taubman College of Architecture and Urban Planning in the University of Michigan.

\section{Water, Infrastructure and Urbanism as Pedagogical Lenses}

The study of interconnected systems, including the relationship between infrastructure, patterns of urban development and water quality, demands approaches capable of negotiating a wide range of scales and time frames. Liquid Planning recognizes that systems approaches require a high level of synthesis and the integrative coordination of knowledge sets, technical skills and collaborative practices. Therefore, the course is structured around several short assignments that teach technical content, visualization techniques and methods of collaboration. A final, longer assignment prioritizes synthesis and challenges traditional disciplinary and politically constructed boundaries.

The links between urban materiality, stormwater runoff, infrastructure failure and water quality have served as the testing grounds for the development of this teaching model for several reasons. First, throughout North America, and particularly within the Great Lakes Basin, combined sewer infrastructure has become one of the most pressing water-quality threats of our time. Such systems utilize a single, subterranean pipe to collect sewage effluent from buildings as well as stormwater runoff from roofs, roads and parking lots. Since the design and construction of these systems, our cities have undergone unprecedented horizontal growth, and the amount of stormwater runoff collected from sprawling metropolises inundates the capacity of infrastructure nearly every time it rains. Inundation triggers failure whereby untreated stormwater and sewage are released directly into streams and rivers. 
To understand the scale of this challenge, we need look no further than the city of Detroit. In January 2010, Dave Battagello published an article titled "Windsor cleans up act as Detroit spews sewage into river" in the Windsor Star. The article quoted Matthew Child, director of watershed restoration for the Essex Regional Conservation Authority, as saying, "The City of Detroit's wastewater treatment plant is the largest source of sewage-related contaminants in the entire Great Lakes." It went on to report that in 2008 and 2009, Detroit's sewer system allowed 37.2 billion gallons of raw and partially treated waste into its waterways. The article also stated that within the same time period, three dozen communities in Metro Detroit dumped a combined 80 billion gallons of excess sewage and other hazardous materials into rivers and lakes - the volume of nearly seven million backyard swimming pools. This trend worsened in 2011, the wettest season in recent history, when the Detroit Waste Water Treatment Plant discharged 47 billion gallons of diluted raw sewage and stormwater into the Detroit and Rouge Rivers (Sierra Club 2012). These repeated events have resulted in a high level of water pollution in the Detroit and Rouge Rivers, which has led to their designation as areas of concern (IJC 1987).

Starting from an understanding of the challenges posed by aging combined sewer infrastructure, Liquid Planning posits that novel design and construction practices are an essential component of metropolitan strategies to reverse infrastructure failure, reintroduce natural processes in the city and engage residents in the process. The specific condition of Detroit, currently undergoing a long-term planning initiative to tackle depopulation (the city has lost more than one million residents since the 1950s peak, to reach a population of 713,777 as registered by the 2010 US Census), presents a perfect ground to examine how design approaches can contribute at multiple scales and foster diverse perspectives. The problem of shrinking cities is an active topic of debate for a range of cities in North America, including Detroit. We share the belief "that a shrinking city-despite its loss of population and its challenged state-is not necessarily dying but is ... in need of new strategies to activate urban life" (Czerniak 2013). At the metropolitan scale, design strategies can respond creatively to aging infrastructure sited within an unevenly and scarcely populated geography. At an experiential scale, spatial and material practices possess a generative capacity to foreground water as a civic and cultural amenity.

Finally, the study of water systems encompasses qualitative and quantitative considerations. Multiple layers depicting the patterns of water flow and related urban systems can be visualized using Geographic Information System (GIS) applications. The resulting spatial data offer opportunities for comparative analysis, cartographic projections, and translation into other software platforms for three-dimensional 
modeling and visualization. In all of these ways, water provides a pedagogical framework that enables students to establish connections across the physical, regulatory and cultural forces that shape contemporary urban conditions.

\section{Teaching Collaborative Scholarship}

To ensure a dynamic and interactive structure, the course blends approaches from three distinct pedagogical formats: 1) seminar (content delivery through lectures and discussion), 2) workshops (coordinated collaborative problem-solving exercises and applied training in GIS and Rhinoceros), and 3) studio (research-design learning through making). Each semester, we facilitate content delivery by aligning the geographical area of study with our current research projects (see Arquero and Maigret 2011).

This mix of pedagogical formats serves four overarching learning objectives: 1) an understanding of trans-disciplinary collaboration that emphasizes dynamic expertise and leadership roles (see Linder 2005), 2) an ability to establish a hierarchy between quantitative evidence and qualitative ambitions that grow out of the initial data analyses, 3) an ability to negotiate multiple and sometimes conflicting definitions of boundaries through design, and 4) an ability to translate design concepts into two- and three-dimensional physical and visual representations that foster communication, identify and/or speculate upon design opportunities and evoke compelling cultural interpretations that transcend disciplinary biases.

Collaboration is a pedagogical priority that is nurtured in several ways. Three of the four assignments require students to work in teams. Students self-organize into disciplinary-diverse teams of three and proceed to work together to complete the assignment. At the beginning of each assignment, we meet with the teams and require them to produce a short written document describing roles and responsibilities and expected outcomes. This makes the structure of the team as transparent as possible and empowers individual performance within group work.

Throughout the semester, the changing nature of the progressive assignments fosters collaboration by requiring a rotation of leadership roles within each team. For example, in the second assignment, students produce cartographic representations utilizing ArcGIS. In this case, the students with training in Urban Planning are the team's "experts," as they have had experience with the software, and they serve as team tutors to help expedite the learning curve of students who are not familiar with the software. Conversely, the third assignment requires students to use Rhinoc- 
eros to construct a digital three-dimensional model and translate this into a file for laser cutting to produce physical components that are assembled. In this case, the architecture students serve as team "experts" and facilitate the learning curve of their colleagues who have never constructed a digital or physical model before.

Discussion sessions, public presentations and the use of pin-ups represent a third opportunity to foster collaboration across the seminar. It is common for individual teams to "discover" a technique other teams can use or to uncover information useful to others. Frequent, short presentations keep all members of the seminar informed about each other's work and facilitate exchange of discovery and references across teams, thereby building a sense of the value of collaborative research. Pin-ups require students to produce printed presentation boards that distill complex relationships into visually compelling arguments. This is a common form of communication in architecture education, and an effective way for students to see their own work in comparison to that of their peers and discuss which techniques are more visually effective. In all of these cases, we emphasize the importance of representation techniques as "ambassadors" of communication across disparate disciplinary approaches and biases.

\section{Fall 2012 Semester Structure and Student Work Examples}

In the Fall 2012 semester, Liquid Planning participated in the "Play\&Grounds" component of the "Sustainability and the HOPE Village Initiative," a unique collaboration between the University of Michigan's Graham Environmental Sustainability Institute and Focus:HOPE, a non-profit organization based in Detroit. This unique partnership allowed students to participate in design research that paralleled the development of an integrated framework for the open space network in the HOPE Village, an area located across the west boundary of Detroit and Highland Park. The class also benefited from an organized site visit to the HOPE Village, access to data from active research, exposure to Integrated Assessment methodologies (see Horning et al. 2009), and an approach to design that fostered the synthesis of these considerations.

In order to frame the current urban dynamics in the Detroit metropolitan area, the semester introduced the ongoing efforts to develop a visioning framework to guide the city's land use reform initiated by Mayor Bing. In his 2010 State of the City Address, Mayor Bing observed, "Strengthening our city will take a long-term strategy for how we use Detroit's 140 square miles more productively. The harsh re- 
ality is that some areas are no longer viable neighborhoods with the population loss and financial situation our city faces. But instead of looking at our land as a liability, we need to begin to think creatively about how it can be a resource as we rebuild our city." Under the Detroit Future City initiative, in 2010 the city embarked on a new planning process with the overarching goal of "improving the quality of life and business in Detroit in the next five to twenty years" (DWP 2012). This process required significant research to update information on existing and projected conditions, and enlisted the expertise of technical teams that joined efforts with city officials, residents and businesses to create a Strategic Framework Plan. This plan, under development during the course of the semester, served as a framework for re-envisioning the open space network in the HOPE Village. The plan classifies the HOPE Village as a "transitional neighborhood," a definition that has significant implications for the implementation and financing of Detroit's future planning efforts in the HOPE Village.

\section{Assignment 1: Long-Term Planning for Detroit and the Hope Village Initiative}

As an introduction to the Detroit Works Project and to HOPE Village's relationship to past and present planning policies, this one-week research project requires multidisciplinary teams to produce a brief presentation summarizing the five strategies of the Detroit Works Project (one team per strategy, Figure 1) and introducing the HOPE Village Initiative (developed by one team). This assignment introduces models of collaborative work and serves as an icebreaker.
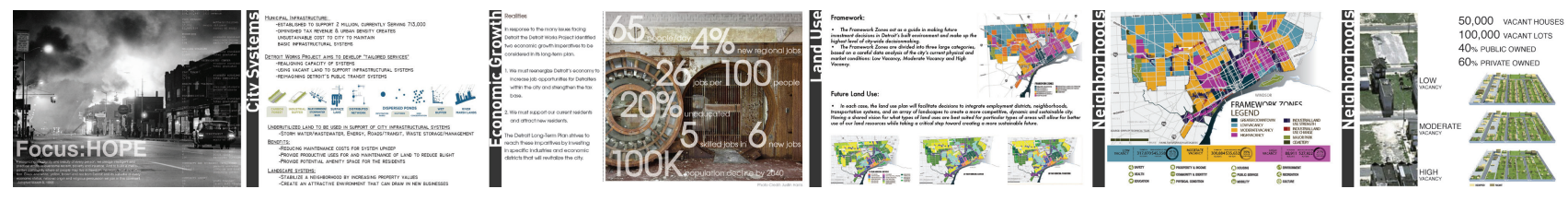

Figure 1

Assignment 2: Cartography through Six Lenses

Assignment 2 interrogates the generic understanding of place and policy as evidenced in the Detroit Works Project. It introduces GIS techniques as tools to generate base cartographies and display spatial and quantitative data. Using HOPE 
Village as the area of study, Assignment 2 practices cartography through six lenses: socio-economic indicators, land use and zoning, transportation infrastructure, public land, neighborhoods and materiality (Figures 2 to 6). The outcome of this assignment enables students to ask and answer focused research questions through the use of geographic information systems. In this assignment, Urban Planning and Landscape Architecture students offer technical software expertise (in addition to software tutorials provided both in and outside of class) and are empowered as team leaders. We utilize a pin-up format to discuss the final assignment boards and identify design opportunities to be explored in assignment 4 . The research and GIS data generated in this assignment are also made available on a shared server and form a collective data set for the course.

\section{Assignment 3: Modeling Geometries of Collection, Percolation and Retention}

Assignment 3 introduces students to three-dimensional digital modeling techniques, laser cutting and physical modeling building skills. This assignment is structured in a manner similar to basic design assignments, typically used in introductory architecture coursework, that teach students spatial abstraction, translation and interpretation skills. The assignment asks students to design a three-dimensional water "machine" that must meet specific, measureable performance criteria. Students are allowed to select one of three design challenges: 1) water collection, 2) water percolation, or 3) water retention. The water machine must be designed within a set of dimensional boundaries and must be fabricated out of components laser cut from a sheet of acrylic material. The final test is run during class when students pour colored water through the models to assess how well the design responses meet the given criteria (Figures 7 and 8).

\section{Assignment 4: Design through the Lens of Water}

Assignment 4 builds on the skills and techniques introduced in earlier assignments and requires a synthetic approach to design. In teams of three or four, students site a small design proposal within the HOPE Village and articulate how the design work is pertinent to the stormwater and cultural concerns explored in the earlier part of the semester (Figures 9 to 14). This assignment challenges students to work 


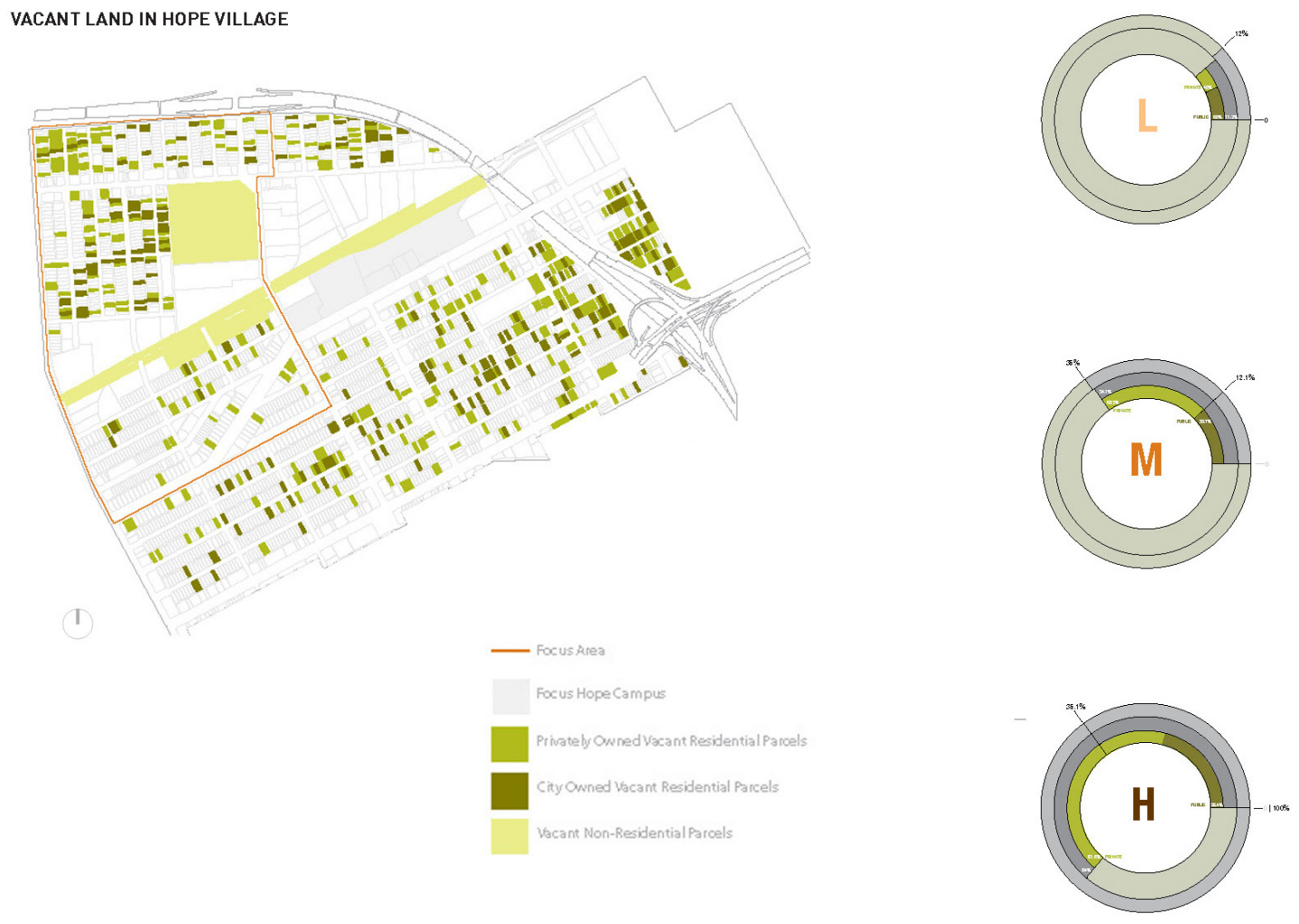

Figure 2

\section{LOW VACANCY \\ 0 to $12 \%$ OF TOTAL BLOCK QUALIFIES AS LOW VACANCY \\ SAMPLE BLOCK: \\ HAS 11.2\% TOTAL VACANCY \\ OF $11.2 \%$ VACANCY, $60 \%$ OF THE PARCELS ARE PUBLICLY OWNED AND $40 \%$ ARE PRIVATELY OWNED \\ MODERATE VACANCY \\ 121 to 35\% OF TOTAL BLOCK QUALIFIES AS MODERATE VACANCY \\ SAMPLE ELOCK \\ HAS $34.1 \%$ TOTAL VACANCY \\ OF $34.1 \%$ VACANCY, $30.7 \%$ OF THE PARCELS ARE PUBLICLY OWNED AN $69.3 \%$ ARE PRIVATELY OWNED}

\section{HIGH VACANCY}

351 to 100 听 OF TOTAL BLOCK QUALIFIES AS HIGH VACANCY

SAMPLE BLOCK:

HAS 64\% TOTAL VACANCY

OF 64\% VACANCY, 38.4\% OF THE PARCELS ARE PUELICLY OWNED AND $61.6 \%$ ARE PRIVATELY OWNED
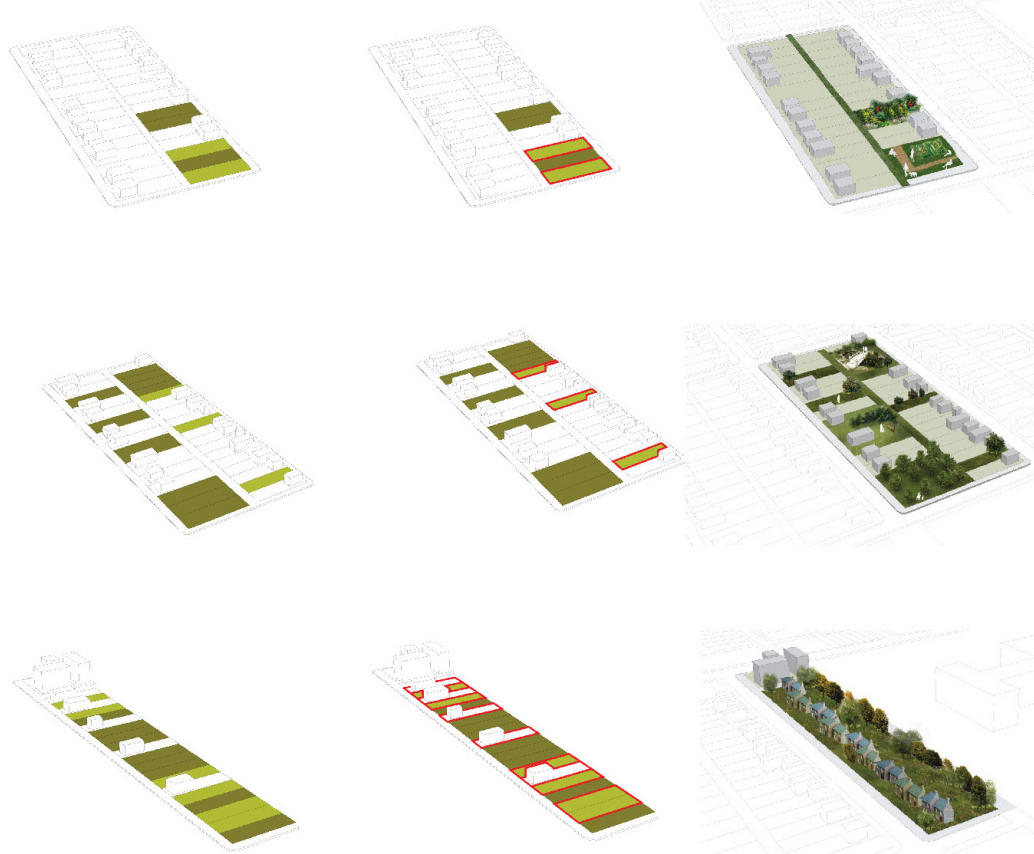
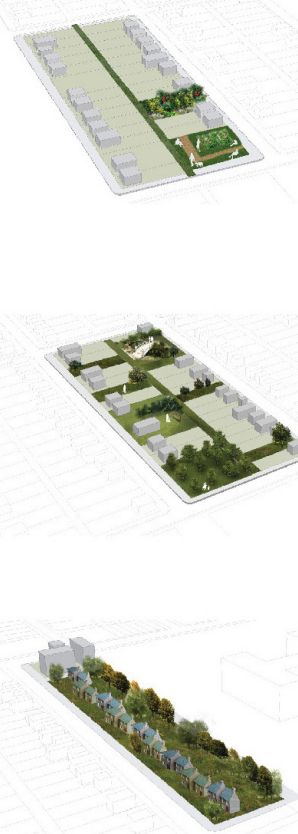


\section{MATERIALITY IN SECTION: A TYPICAL RESIDENTIAL BLOCK}

Houses, cvergrown lots and paved roads are the building blocks to a complex materia pallette that comprises the section of a typical residential block in the Hope Village study area An understanding of roofs, slabs, basements, and noot structures add an additional layer of material relationships to the section, allowing us to begin to visualize relevant adiacencies and iuxtapositions at various locations through the block Detroit is especially vulnerable to groundwater contamination due to the thinness of glacial drift deposits. These deposits, comprised of soll and rock particles, lay on top of the bedrock that houses groundwater underneath. As a result of its thin top layer, Detrolt's resh groundwater supply is at a higher risk than other geographies in Michigan. To combat the pollution associated with runoff water into the soll, natural features can improve water absorption before the polluted materials reach the bedrock. One potential site for scaled impact may be the typical compacted gravel alley that runs through most residential blocks. Currently most of these alleys exist in disrepair and impressive overgrowth, and are a common site for illegal dumping

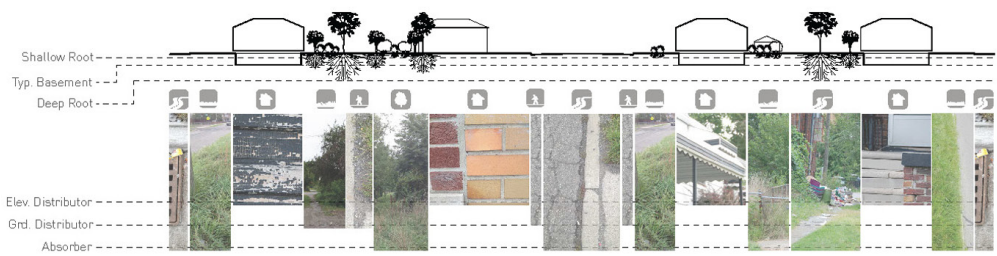

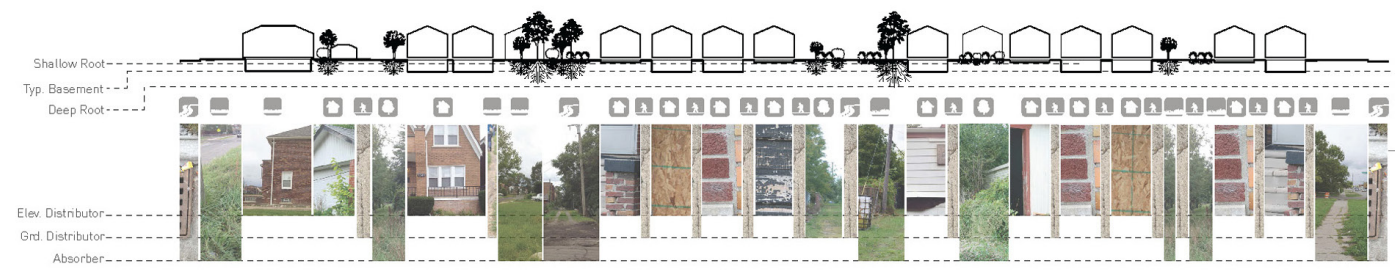

Figure 4

PERMEABILITY OF SURFACES BY ZONING

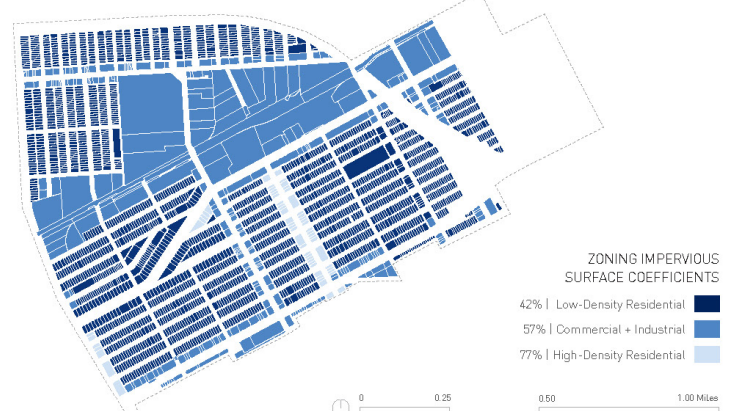

PERCENTAGE OF LAND BY ZONING

227.06 ACRES $149 \%$

10.50 ACRES $102 \%$

225.42 ACRES $149 \%$
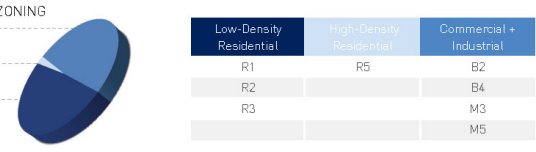

The porosity of land based on zoning is divided into three categories, [1] low-density and [2] high-density residential and [3] commercial/ind ustrial. The standards for the above impervious surface coefficients IISC] come from the Environment Protection Agency (EFA). Permeability is represented by a blue gradient, the darker the color, the more pervious the surface is expected to be

Based on the map above, low-density residential, with an impenrious surface coefficient of $42 \%$, should hold the most water However this $42 \mathrm{~g} / \mathrm{S}$ C can differ greatly depending on the land use and the amouth of physical or natural elements on each parcel. This is important as roughly half [49\%] of the land is zoned as low-density residential.
PERMEABILITY OF ROADS BY CLASSIFICATION

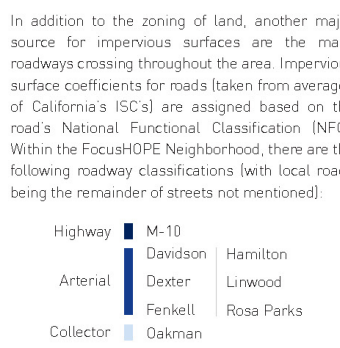

In general, highways experience the greatest level of permeability for stormwater $[47 \%$ 15C], due to their lange gravel shoulders and vegetated buffers. Additionally, arterial roads [77\% ISC] provide greater opportunities for water absarntion than most local [87\%] or collector mads [900\%

Within the FocusHOPE Neighborhood, local roads Within the focus Given that locat rogds have the second highest ISC,

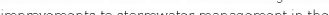

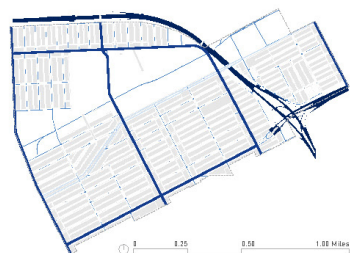

ROAL IMPERYIOUS SURFACE COEFFICIENTS 47\% | Highway
$77 \%$ | Arterial
$90 \%$ | Collector

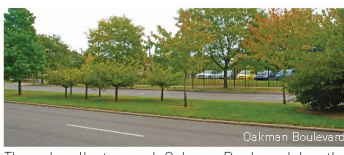

The only collector road, Dakman Boulevard, has the highest ISC and accounts for $3.8 \%$ of the roadways towever. Datman is enclosed by ned ans which likely mitigte some of the ston moter pollon and runoff.

PERCENTAGE OF ROADWA'S PRESENT IN THE FOCUSHOPE NEIGHBORHOOD BY LOCAL I 726\% THEIR NATIONAL FUNCTIONAL CLASSIFICATION

ARTERIAL I 14.5\% COLLECTOR $\mid 7.8 \%$ HIGHWAY | $5.9 \%$

Figure 5 
PERMEABILITY DETERMINED BY GROUND COVER I RESIDENTIAL A NEIGHBORHOOD BLOCK

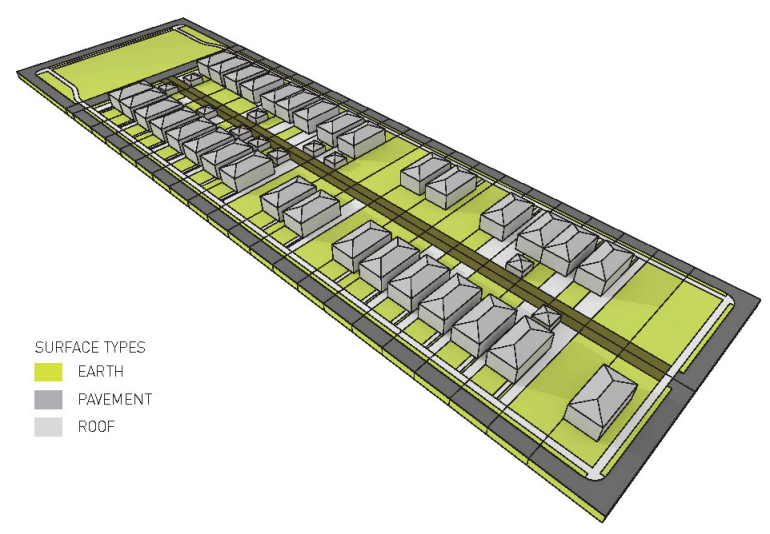

PERMEABILITY DETERMINED BY GROUND COVER I COMMERCIAL A COMMERCIAL BLOCK

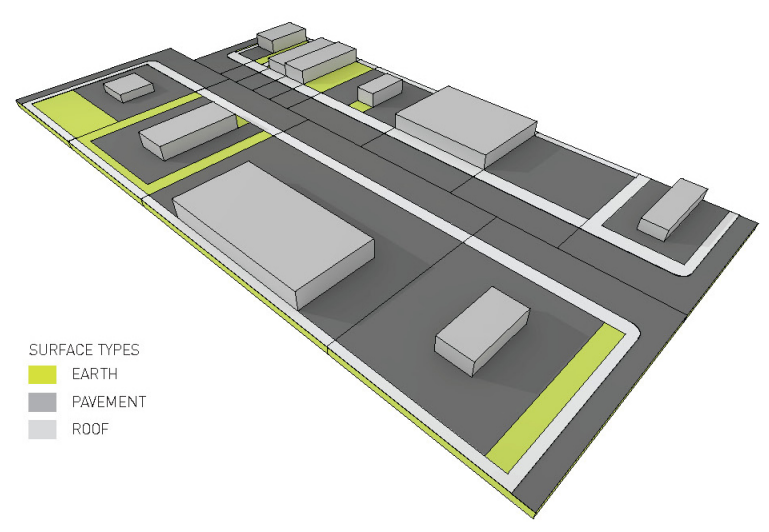

GROUND COVER TYPOLOGIES
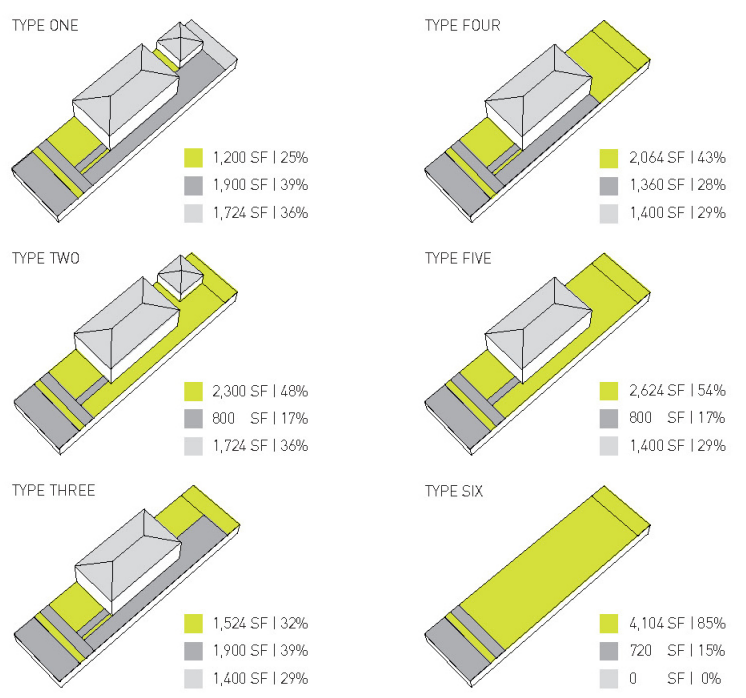

$2,624 \mathrm{SF} / 54 \%$ 800 SF I 17\% -1,400 SF $129 \%$

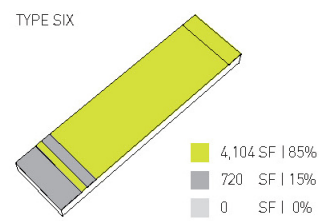

GROUND COVER TYPOLOGIES
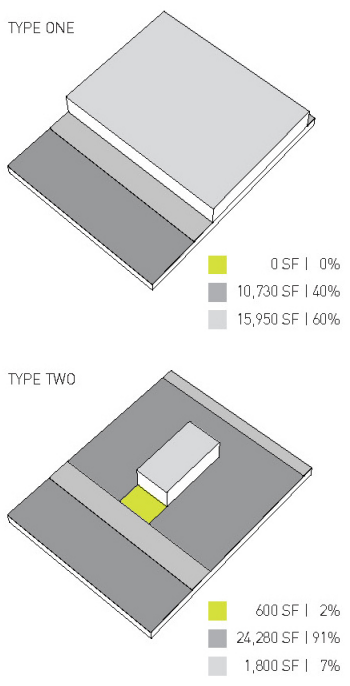
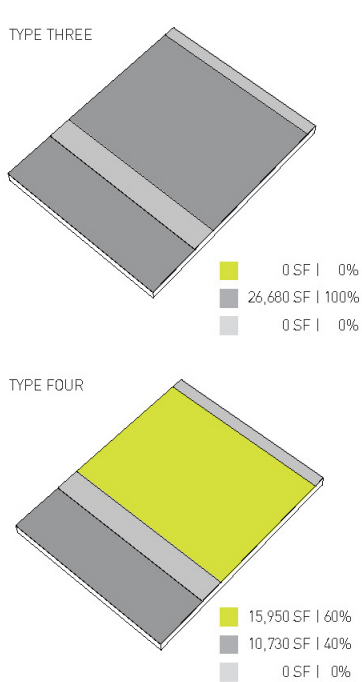

Figure 6 

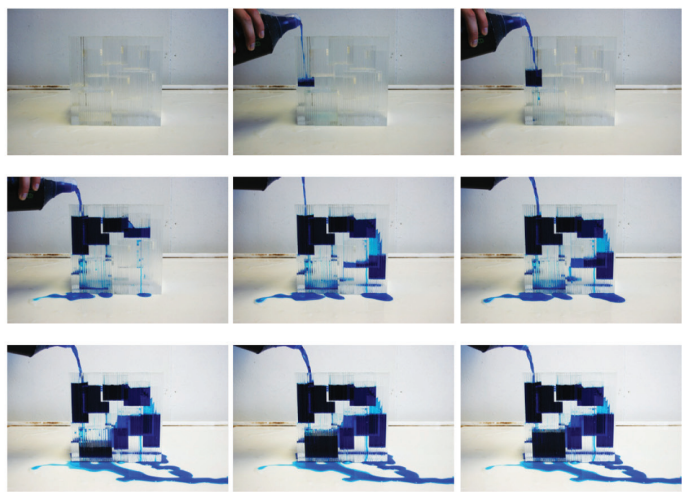
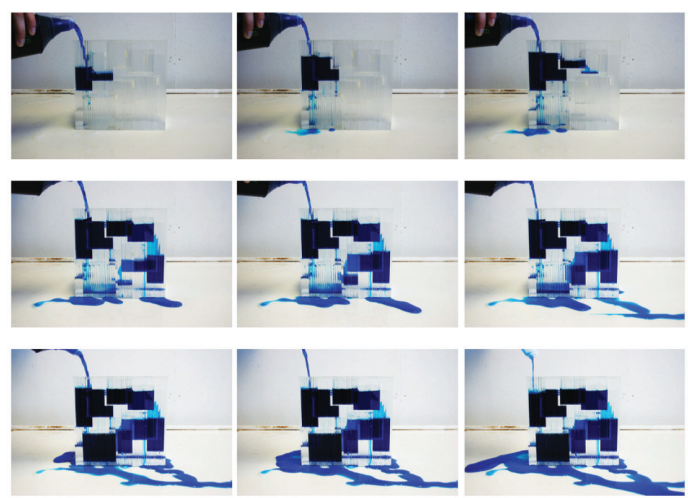

Figure 7
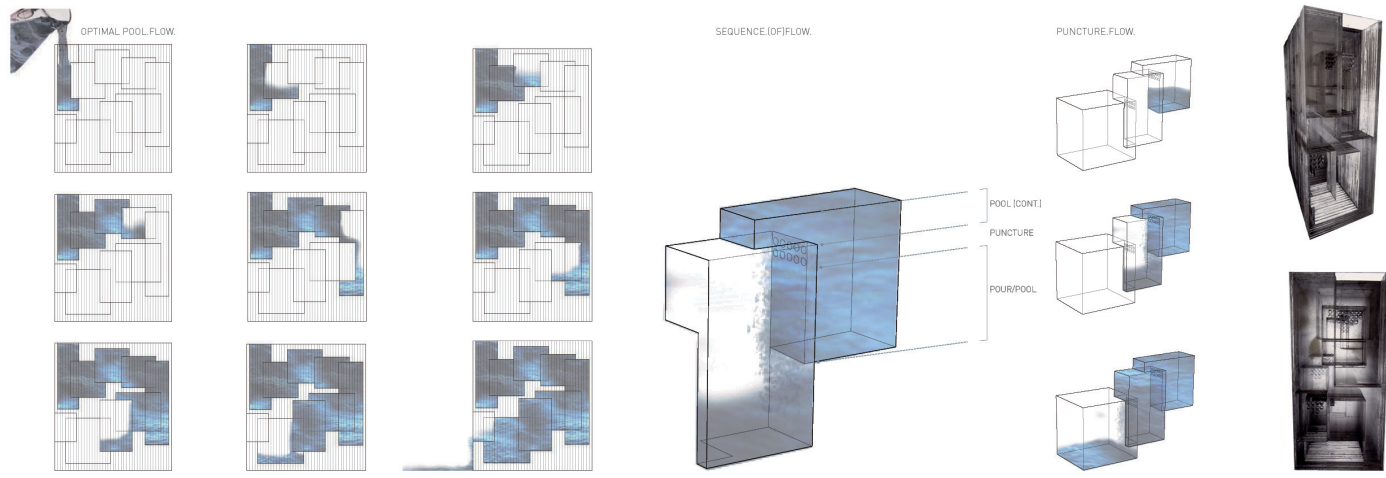

Figure 8

as a team on design problems that do not have clear right or wrong responses. Ultimately, students learn to navigate interpersonal communication, complex data analysis and creative thinking to conceive and communicate innovative and hydrophilic approaches to stormwater design within the HOPE Village.

\section{Conclusion}

Liquid Planning provides a pedagogical platform for collaboration between students in urban planning, architecture, landscape architecture and natural resources as they work towards the design of innovative approaches for integrative water urbanism. This approach prioritizes the exposure to design research as a means to build the skills and expertise necessary to study problems with high degrees of complexity 


\section{RUNNING IN CIRCLES}

Running in Circles, seeks to mediate stormwater run off in Detroit and investigate its playfulness as result of its juxtaposition with schoolyards. As a neighborhood planning unit, the school in Detroit was the loci of the community. However changes in Public School District policies determined that students could go to any school within Detroit that they chose. This generally meant that kids with access to a vehicle and economically well off could travel further to go to good schools while the less fortunate could only attend the nearest walkable school, leading to an inequality in educational facilities. This project seeks to re-establish the schoolyard as a catalyst for the community by opening up the site to its neighbors and invite them to partake in liquid activities. Storm water is collected from the street and filtered through series of wetlands while also being chemically treated so that it is clean enough to interact with. The water travels into various reservoirs and design elements where it can be used for education or amusement. While taking place in the FocusHope community, the projects can span across 5 school sites and perhaps act as a larger model for the rest of Detroit. The project, can take advantage of grants coming through FocusHope as well as educational grants while using the community to build and sustain the project. With children as the focus, they can take part in learning how to care for their community and experience new ways to play.

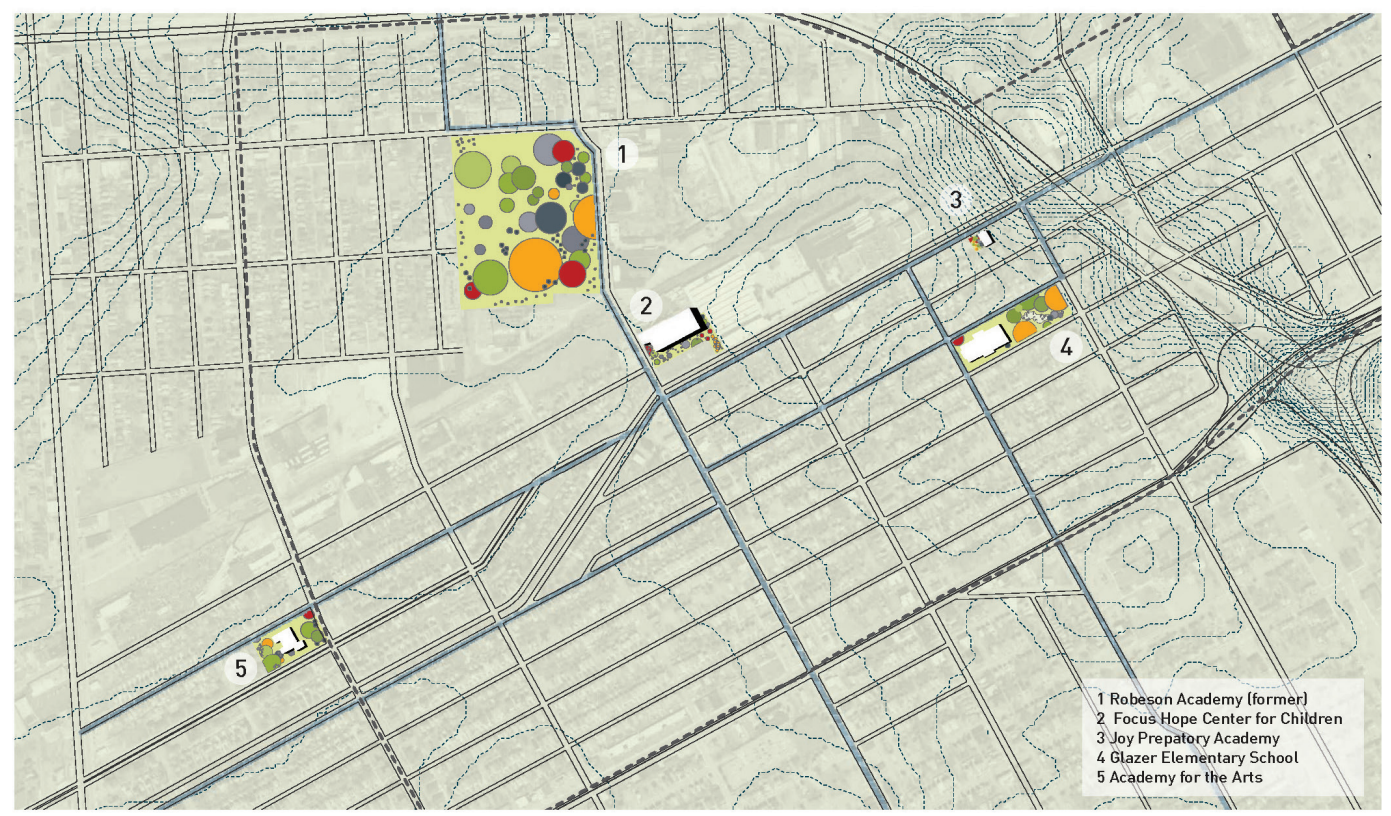

Figure 9 
DETROIT PUBLIC SCHOOL SPREAD

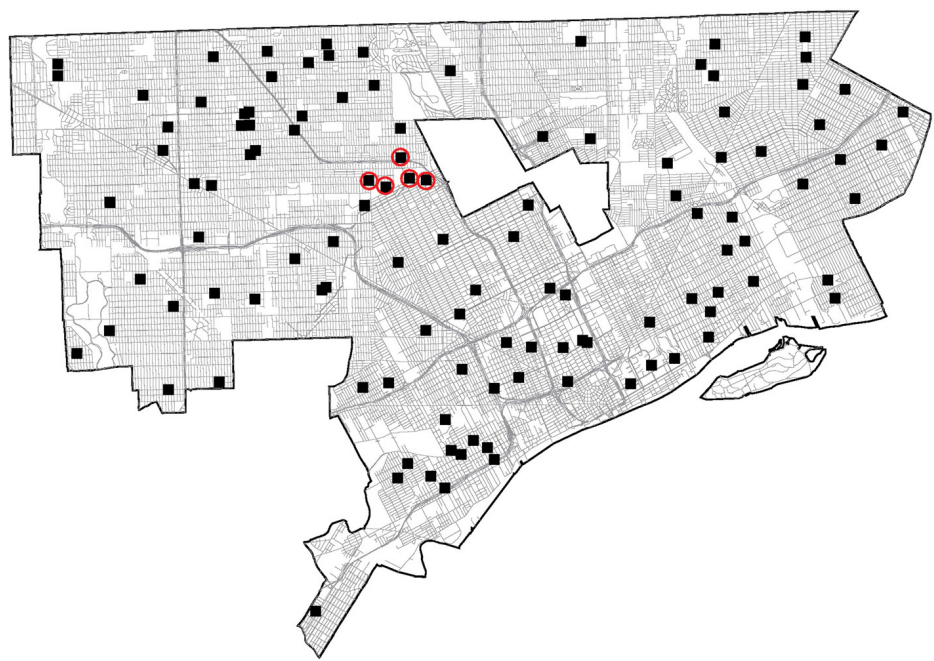

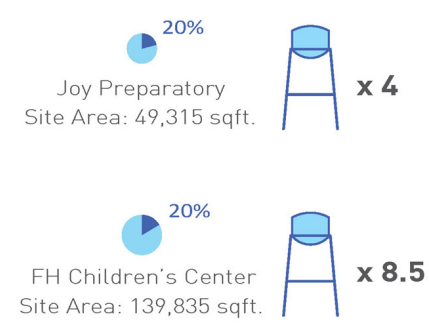

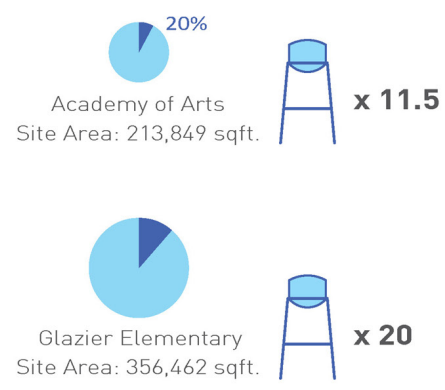

Figure 10

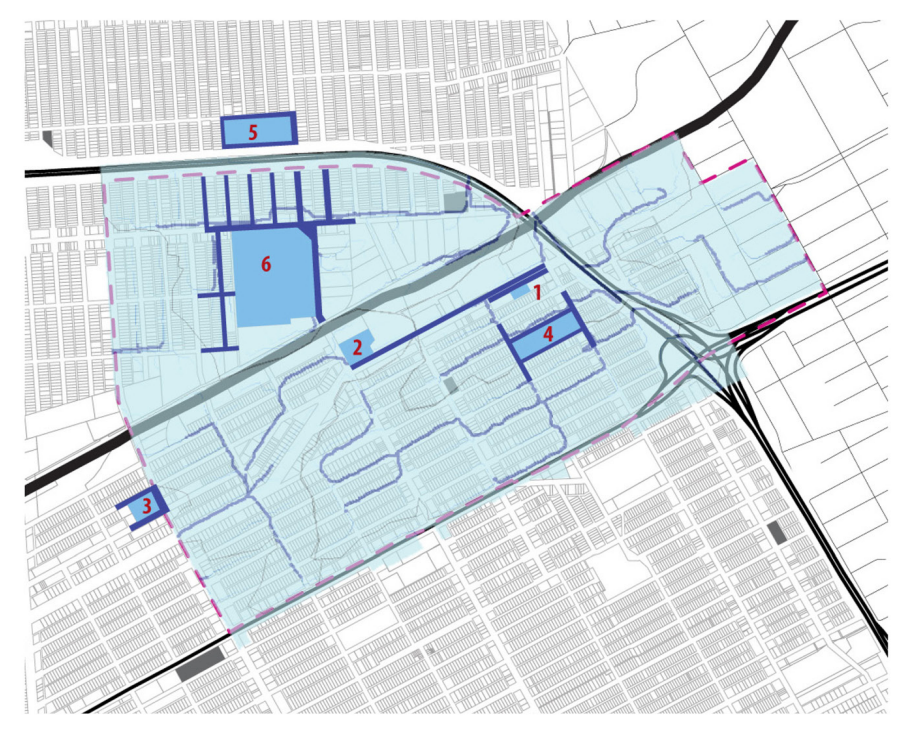

Water Calculation Diagram
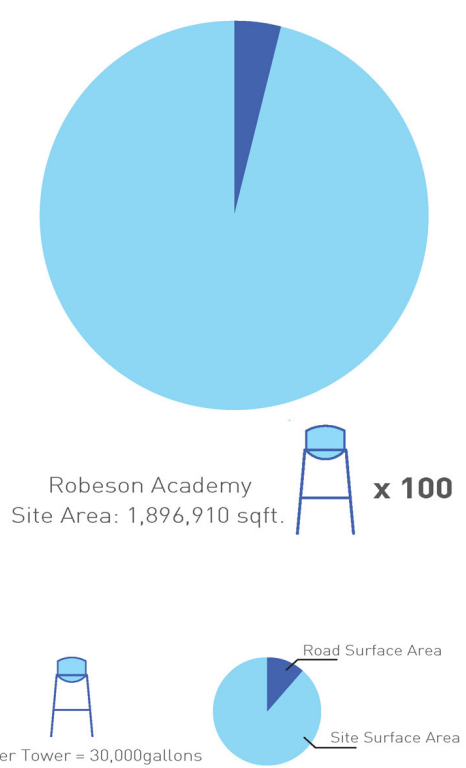

Figure 11 
Michigan Journal of Sustainability

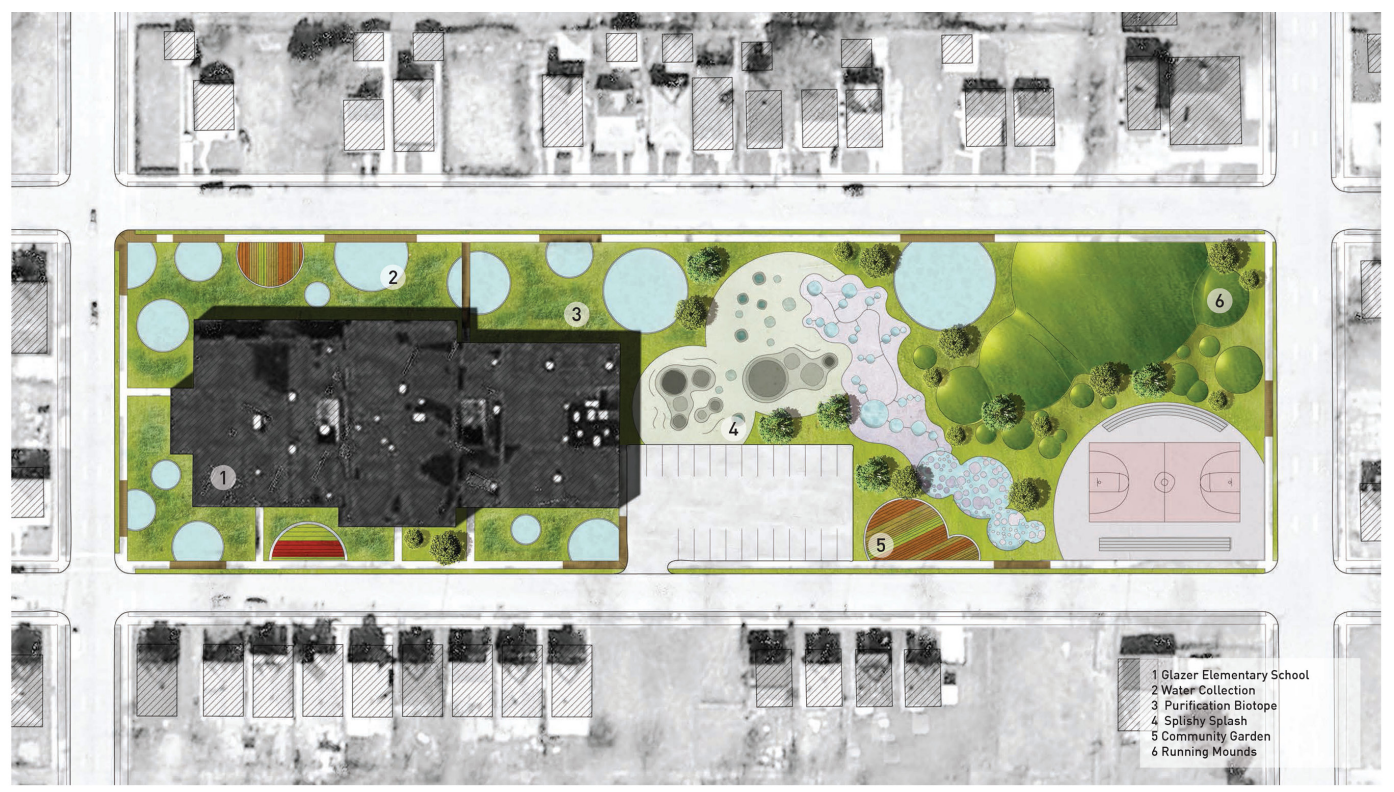

Figure 12
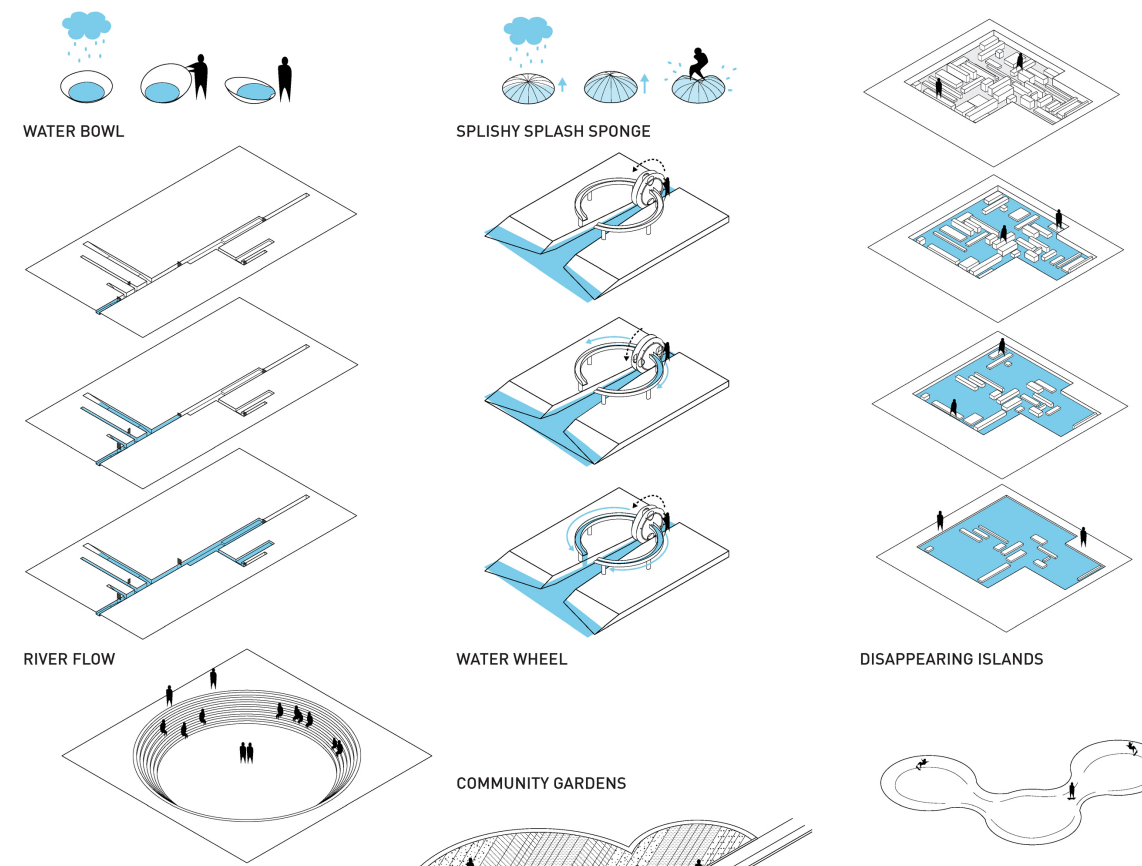

AMPHITEATER FOR SKATING

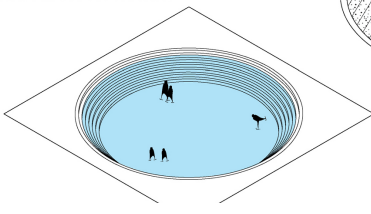

COMMUNITY GARDENS
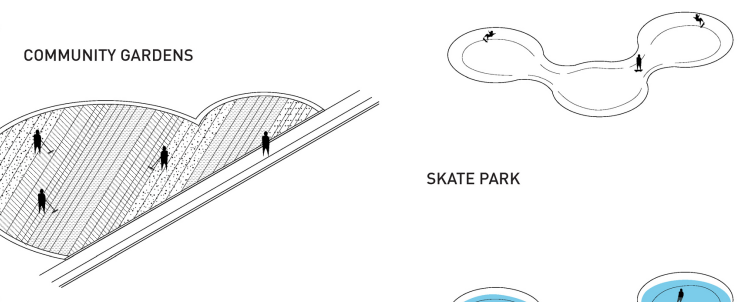

SKATE PARK

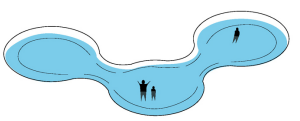

Figure 13 

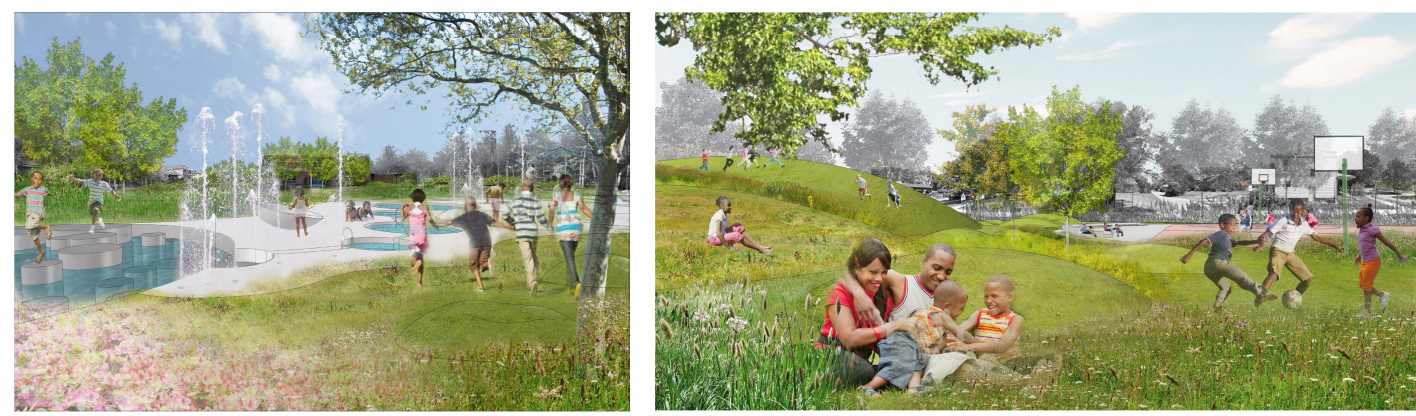

Figure 14

\section{FOLLY THE LEADER}

WHY GREEN INFRASTRUCTURE?

DETROIT WASTE WATER AND SEWERAGE SERVICE AREA

OVERLOADED

STORM WATER AND SANITARY WASTE WATER

946 SQUARE MILES

$35 \%$ OF MI POPULATION

3,433 MILES OF SEWER LINES

727 MILLION GALLONS OF FLOW PER DAY

76 COMMUNITIES THROUGH WAYNE, OAKLAND, MACOMB, ST CLAIRE, LAPEER, GENESSEE, WASHTENAW, MONROE

Figure 15
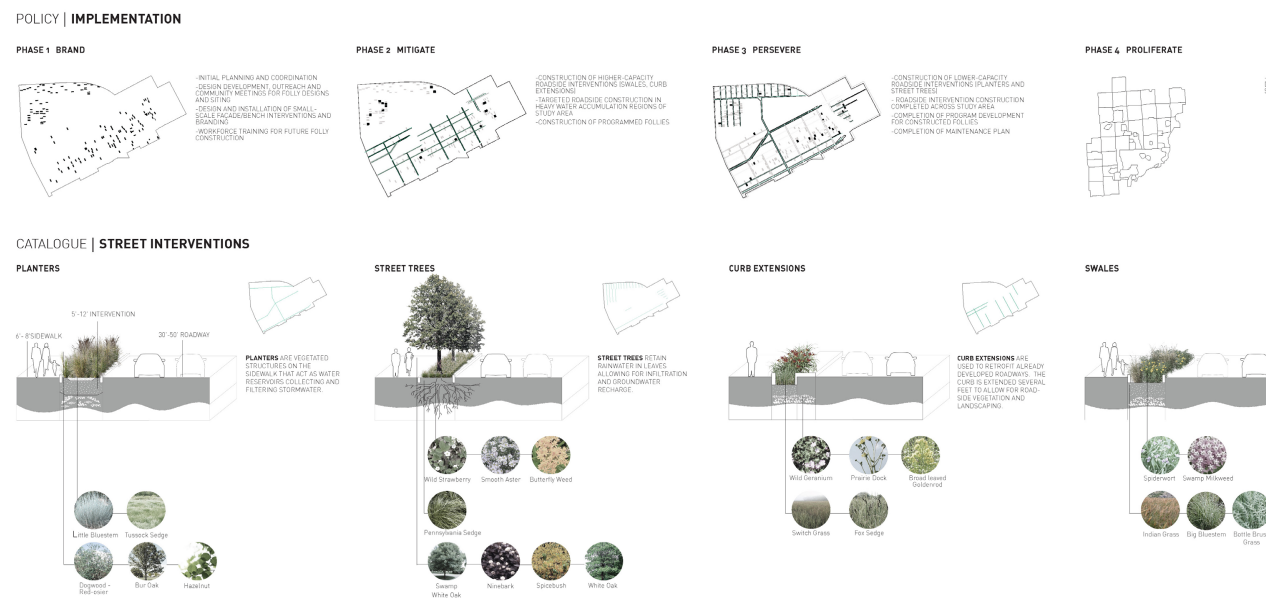

(2) 20

1.6.

0019 


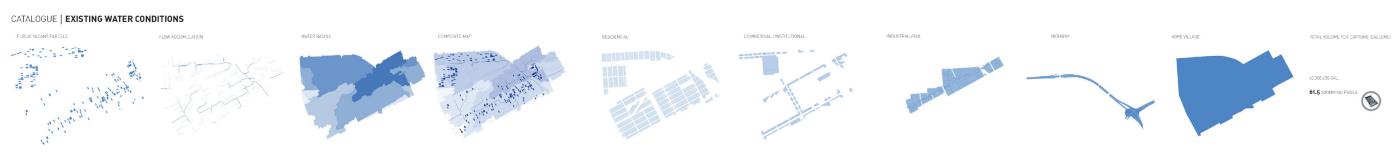

Figure 17
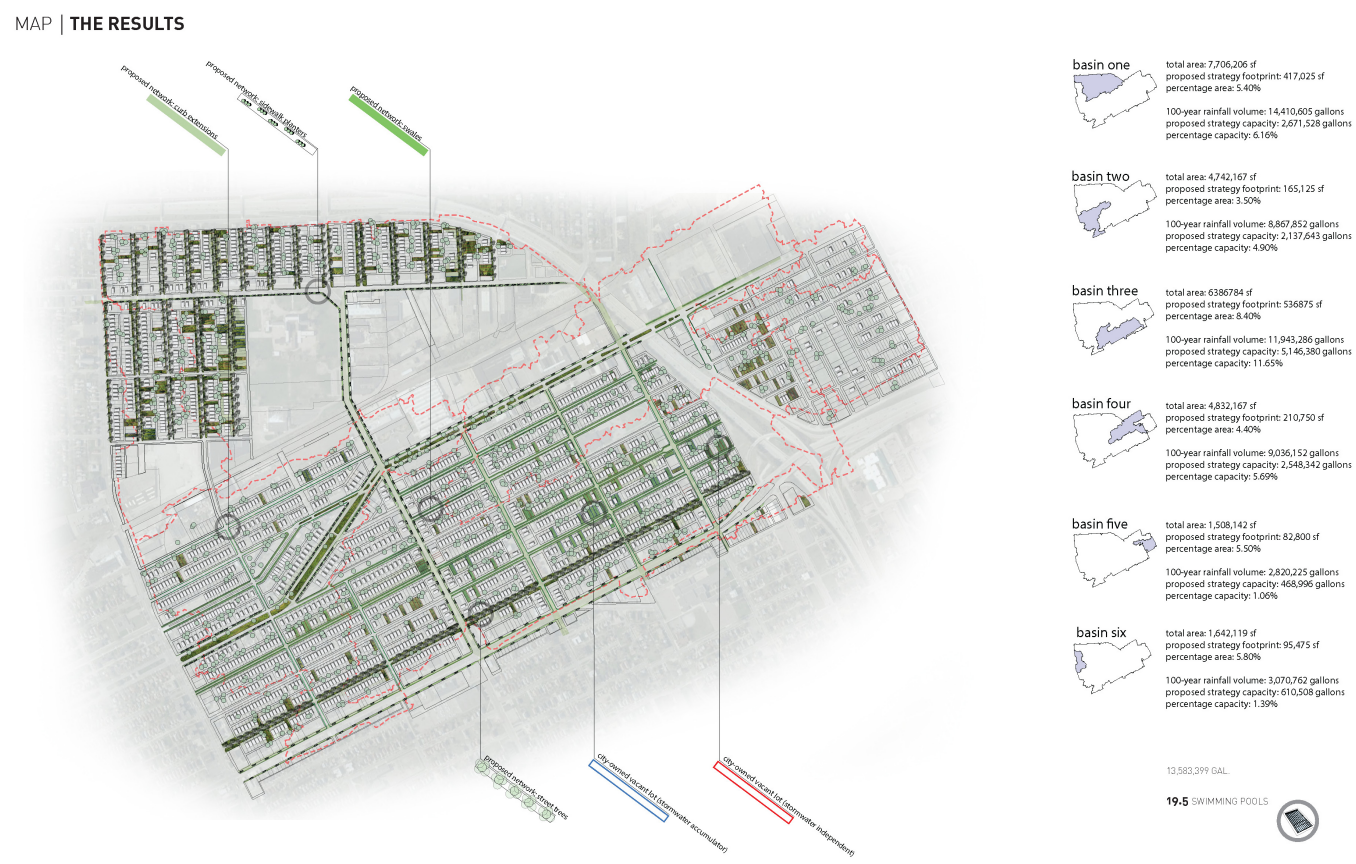

Figure 18 
CATALOGUE | VACANT LOT AGGREGATES

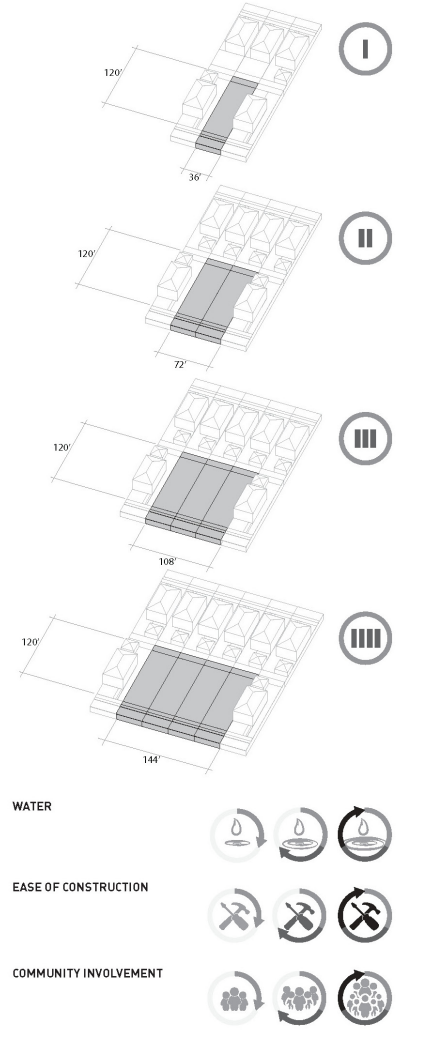

Figure 19

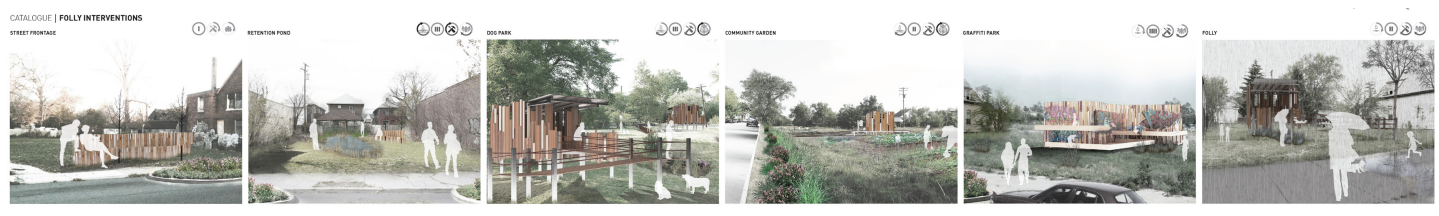

Flgure 20 
and inter-connectivity. Towards this end, the course fosters a technologically literate approach that positions visual representation as a mode of inquiry and a vehicle for the dissemination of the research to wider audiences.

Liquid Planning leverages cross-platform software analyses and visual representations as students work towards the synthesis of quantitative and qualitative perspectives and foster an imaginative integration of urban and natural systems. If students are to gain experience within the increasingly complex framework of systems-scaled, sustainable design projects, they need learning experiences in new technological approaches such as the marriage of GIS with digital fabrication techniques. When asked to challenge many types of boundaries, including disciplinary, perceptual, and political boundaries, students discover previously unimagined opportunities to approach cultural and environmental concerns in innovative ways through design thinking. Additionally, by introducing students to structured collaborative research, Liquid Planning educates young design and policy professionals who will be increasingly challenged to contribute to integrative and participatory research models that address the complex challenges of our time.

\section{List of Figures}

Figure 1: Collective class work responding to Assignment 1, the study of the Detroit Works framework and the Focus Hope mission (selected images from all groups' work).

Figures 2 and 3: Work from Assignment 2 showing analysis of land vacancy in the Hope Village.

Students: Public Land Team (Leigh Davis, Cole Gehler, Landry Root, Catie Truong).

Figure 4: Work from Assignment 2 showing analysis of materiality at the urbanblock level in the Hope Village.

Students: Materiality Team (Paul Fromm, Zachary Gong, Laura Haw, Eric Pasche).

Figures 5 and 6: Work from Assignment 2 showing analysis of land use and zoning lot typologies by way of permeability and materiality in the neighborhood at the urban-block level.

Students: Materiality Team (Paul Fromm, Zachary Gong, Laura Haw, Eric Pasche) 
Figures 7 and 8: Water model test: A geometry of retention. Water enters in one location, flows for a minimum of 20 seconds, and exits out of another location through a system of adjacent pour-spill voids. The water exits each prism and flows into the adjacent one through a collection of $1 / 8$ " diameter perforations.

Student: Landry Root

Figures 9 to 14: "Running in Circles": Work from Assignment 4 showing playgrounds as opportunities for stormwater management. Images displayed: (8) the design rationale, (9) Detroit Public Schools and the ones in the Hope Village area of influence, (10) water calculations for the Hope Village, (11) the design site plan for the Glazer Academy, (12) the water components, and (13) the renders of the proposal.

Students: Robin Chhabra, Ryan Ornberg, Reshmi Ravidran, Sascha Topolnytska

Figures 15 to 20: "Folly the Leader": Work from Assignment 4 showing small community-built structures as opportunities for stormwater management.

Images display: (14) the design rationale, (15) implementation strategy and street interventions, (16) water conditions catalogue, (17) urban watersheds in the Hope Village, (18) vacant-lot aggregation, and (19) the renders of the proposal. Students: Landry Root, Catherine Truong, Leigh Davis, Zachary Gong

\section{References}

Arquero, Maria, and Jen Maigret. June 2011. "Liquid Matters." Scales of Nature. Proceedings of the International Federation of Landscape Architects World Congress, Zurich, Switzerland.

Bing, Dave. 2010. “State of the City, 2010.” http://www.detroitmi.gov/DepartmentsandAgencies/ MayorsOffice/StateoftheCity2013/StateoftheCity2010.aspx.

Czerniak, Julia. 2013. Formerly Urban: Projecting Rustbelt Futures. New York: Princeton Architectural Press.

DWP (Detroit Works Project Long-Term Steering Committee). 2012. Detroit Future City: 2012 Detroit Strategic Framework Plan. Detroit: DWP.

Horning, Andrew, Don Scavia, Lynn Vaccaro, Jennifer Read, and James Diana. 2009. "Tackling Wicked Problems through Integrated Assessment: A Guide for Decision Makers, Project Leaders and Scientists." Ann Arbor, Michigan: University of Michigan.

IJC (International Joint Commission). 1987. Biennial Report on Great Lakes Water Quality:

Technical Report. Windsor, Ontario, Canada: IJC.

Linder, Mark. 2005. “TRANSdisciplinarity." Hunch: The Berlage Institute Report 9:12-15.

Sierra Club, Michigan Chapter. 2012. "Great Lakes Protection.” http://michigan.sierraclub.org/ issues/greatlakes/greatlakesprotection.html. 